\title{
Tecno-arte-poesia no Brasil
}

\author{
Jorge Luiz Antonio \\ Bolsista FAPESP \\ Pós-doutorando - IEL-UNICAMP
}

\begin{abstract}
Resumo: Podemos delimitar geograficamente a poesia digital e denominá-la de brasileira, norte-americana, alemã, espanhola, francesa, etc.? A partir dessa questão, o autor apresenta um panorama da tecno-arte-poesia no Brasil antes e depois do surgimento dos computadores individuais e coletivos. Palavras-chave: poesia brasileira contemporânea, poesia e novas tecnologias, tecno-arte-poesia.
\end{abstract}

\section{Introdução}

Em qualquer tipo de estudo da poesia digital no Brasil, ou em outro país, é importante delimitar e conceituar esse tipo de poesia contemporânea: os termos no Brasil, do Brasil ou (poesia digital) brasileira precisam ser contextualizados com a maior clareza possível, como sendo processos criativos, que envolvem poesia, artes, design e tecnologia, de poetas que vivem no Brasil; que nasceram no Brasil; estrangeiros que para aqui vieram e contribuíram com a tecno-arte-poesia, que a aprenderam em outros países ou que a desenvolveram aqui; merecem referências as situações especiais, como as homenagens, quando pessoas de outros países fazem poesia digital em língua portuguesa. Além dos 
aspectos individuais de cada poeta, é importante verificar se esses poetas formam ou formaram grupos no Brasil, se participam ou participaram de eventos (congressos, festivais e exposições coletivas e/ou individuais) no Brasil ou em outros países. Faz-se necessário verificar se o idioma dessa tecno-arte-poesia, em sua grande maioria, é a língua portuguesa praticada no Brasil, com traduções para outras línguas (inglês, espanhol, francês, alemão, etc.). Também é importante saber se o servidor que hospeda o sítio onde se encontram as poesias digitais se localiza no Brasil ou se a publicação digital (disquete, CD, CD-ROM, DVD, pendrive, etc.) foi feita no Brasil, mesmo que em coeditoria com editoras estrangeiras, para distinguir de publicações de brasileiros em sítios e mídias de outros países. Vale enfatizar, também, que o conteúdo dessa tecno-arte-poesia deve fazer parte da expressão artística da cultura brasileira. Toda essa delimitação se faz necessária para determinar a história da poesia digital no Brasil e ajuda a estabelecer um corpus, possibilita um mapeamento, permite o estabelecimento de gêneros, oferece uma visão panorâmica, fornece subsídios para a formação de antologias, etc.

Podemos usar indistintamente os conceitos de tecno-arte-poesia, poesia digital, poesia eletrônica e suas extensões ou desdobramentos como videopoesia (especialmente aquela surgida a partir da existência das câmeras e filmadoras digitais e do surgimento do programa YouTube) ou poesia sonora, mesmo tendo em vista as suas respectivas especificidades.

\section{Tecno-arte-poesia}

A tecno-arte-poesia é um tipo de poesia contemporânea, que mantém e apresenta um vínculo com as poesias existentes anteriormente, pois representa uma continuação ou um desdobramento, tem suas raízes nos procedimentos da poesia modernista das vanguardas do início do século XX e é uma continuação da poesia concreta e da poesia visual. Por ter procedimentos experimentais bastante acentuados e predominantes, é considerada como um desdobramento ou continuação da poesia experimental, uma denominação geral utilizada por criadores e teóricos de vários países.

O percurso dos meios em que a poesia vem sendo apresentada ajuda a compreender essa continuidade que chega à tecno-arte-poesia: depois de ter sido poesia oral e acompanhada de instrumentos musicais na Antiguidade, ela tem existência no meio impresso, isto é, bidimensional. Assimilou os recursos das 
artes (pintura, desenho, escultura, arquitetura, música) e passou a se concretizar no espaço físico, no meio tridimensional, como objeto artístico, à semelhança de um desenho ou de uma pintura (poesia visual) ou de uma escultura (poesia-objeto). Depois, adaptada à linguagem binária dos computadores, tornou-se simulação e foi para o ciberespaço gradativamente, à medida que a tecnologia computacional foi se transformando: a execução do programa, antes totalmente apresentada em forma impressa, foi migrando para uma exibição na tela do computador, até tornar-se um texto eletrônico de circulação apenas no meio digital.

Ela é formada por palavras, grafismos, imagens estáticas e/ou imagens animadas e sons: todo esse conjunto é elaborado parcialmente ou totalmente por processos digitais, portanto, torna-se um texto eletrônico e/ou hipertexto e/ou hipermídia, e passa a existir num arquivo digital ou ciberespaço ( $e$-book, rede digital, nos seus mais diferentes suportes eletrônicos: CD, CD-ROM, DVD, e-reader, pendrive, etc.) e configura-se como um produto cibrido ${ }^{1}$ desde os seus primórdios.

O entendimento desse tipo de poesia contemporânea passa por um aspecto interdisciplinar e/ou multidisciplinar e/ou transdisciplinar, daí a razão de ser denominada de tecnopoesia ou tecno-arte-poesia. Há um predomínio de relações, diálogos ou negociações semióticas com os processos criativos artísticos, de design, tecnológicos, comunicacionais e poéticos.

Em virtude de ser uma poetização das tecnologias digitais, que se transformam constantemente, a denominação para esse tipo de fazer poético apresenta uma variedade que indica o tipo de tecnologia digital utilizada - computer poetry, poesia informática, texto computacional, tecnopoesia, ciberpoesia, poesia cibertextual, tecno-arte-poesia, poesia do clique, poema pop-up, web poesia, poesia hipertextual, poesia hipermídia, etc.

Sua existência ocorre por intermédio da simulação e da mediação poeta/máquina de maneira total, parcial, ou por meio de uma relação cíbrida (meios físicos e meios digitais).

A linguagem da poesia digital apresenta uma textualidade eletrônica que, em muitos casos, tem hipertextualidade, hipermidialidade, interatividade. Há processos de criação e participação colaborativos, parcerias de autorias e processos coletivos de criação. A partir da existência das redes sociais, a poesia digital ocorre em ambientes virtuais multiusuários. Com o desenvolvimento das tecnologias móveis e sem fio, ela também sofre algumas adaptações e passa a circular nesses meios.

1. Trata-se de um hibridismo que se faz com os componentes da cibercultura. 
É uma poesia que se transforma com os processos artísticos e de design e, principalmente, com os processos tecnológicos e está vinculada aos estágios da tecnologia e à sua rápida obsolescência, necessitando transformação, mudança e adaptação na velocidade do surgimento dos hardware e software. Felizmente, nos dias de hoje muitos programas simuladores de processos digitais desativados, como os emuladores, estão resgatando processos criativos dos pioneiros. Também há programas que convertem as diferentes versões de software e há os que substituem os anteriores e, por isso, já existem obras de recriação de antigas poesias digitais. ${ }^{2}$

A poesia digital tem duas fases principais: a dos computadores isolados e a dos computadores interligados em redes digitais. ${ }^{3}$

O período dos computadores isolados tem início em 1959 com os grandes computadores que usavam diretamente linguagem de programa, ou seja, com pouquíssimas interfaces e o resultado, em forma impressa, era escolhido pelo poeta-programador. O surgimento do computador pessoal trouxe uma maneira mais fácil e individual de trabalhar com programas simples e contou com algumas interfaces, como: mouse e monitor de televisão.

A criação do modem e da WWW gerou o computador em rede e aumentou o ciberespaço, criando uma cibercultura ou second life, que continua se desenvolvendo e se aperfeiçoando até os dias atuais. O computador pessoal e individual tornou-se um computador coletivo e universal. E-mails, grupos eletrônicos de discussão, sítios, blogse redes sociais permitem uma divulgação em tempo real de praticamente tudo na vida das pessoas. O poeta pode publicar seus poemas enquanto estão sendo pensados e escritos e pode aprender rapidamente a usar os mais diferentes programas e poetizá-los. Para fazer isso, ele conta com homepages, blogs, sites, redes sociais e diferentes tipos de tecnologias wireless.

As tecnologias da comunicação (jornal, cinema, rádio, televisão, vídeo) também assimilaram as tecnologias computacionais, ocorrendo miniaturização e potencialização: surgiram as tecnologias móveis, como os telefones celulares e seus derivados, os computadores portáteis (laptop, notebook, netbook), os e-readers e os tablets.

2. O exemplo mais significativo é o resgate de Stochastiche Texte, de Theo Lutz, de 1959, por Johannes Auer em 2005.

3. Pode-se afirmar que uma terceira fase tem início com as tecnologias móveis e sem fio, que ainda se encontra pouco explorada. 
A poesia digital é um produto da cibercultura ou da cultura digital e, portanto, pode ser chamada de ciber-arte-poesia ou tecno-arte-poesia. Podemos entender o percurso da tecno-arte-poesia a partir de três momentos, não necessariamente em ordem cronológica ou realizado por um mesmo poeta ou por um grupo de poetas de tendências criativas semelhantes, pertencentes ou não a uma mesma geração: a tecnologia é o tema da poesia; a poesia metaforiza e imita os procedimentos da tecnologia; ocorre a poetização da tecnologia.

\section{História 1: antes do computador}

Tecno-arte-poesia é uma estrutura conceitual que favorece a compreensão de dois grandes momentos - antes e depois do computador -, e pode ser entendida como uma tecno-arte-poesia geral e uma particular ou digital, com base nas negociações semióticas da poesia com os processos artísticos, de design, científicos e tecnológicos em geral e nas negociações com os processos digitais em particular.

As relações entre poesia, arte, ciência e tecnologia ocorrem desde os primórdios da poesia. O estágio do conhecimento científico, técnico e tecnológico de cada época foi assimilado pelo poeta e, por meio de processos criativos, incorporado à poesia. A poesia eletrônica é um dos resultados de uma série de experimentações poéticas que ocorreram desde o início do século XX, que assimilaram os procedimentos das mídias impressas (livros, revistas, jornais, anúncios publicitários) e eletrônicas (fotografia, cinema, rádio, televisão, vídeo, computador, Internet, WWW). O computador, em todas as suas gerações, também forneceu possibilidades de uso criativo para o poeta. A poesia eletrônica não é uma criação descontextualizada ou surgida do nada: há percursos anteriores que indicam procedimentos capazes de ser entendidos como precursores, devido a processos criativos semelhantes, especialmente no período que abrange o final do século XIX até a primeira metade do século XX, tanto no Brasil como em outros países.

Para o limite deste artigo, ${ }^{4}$ faz-se necessária uma síntese da tecno-arte-poesia geral, que pode começar com duas significativas referências do século XIX: Memórias póstumas de Brás Cubas (1881), de Machado de Assis, pode ser considerado como o primeiro trabalho em prosa, em que um autor explora

4. Uma visão mais aprofundada encontra-se no capítulo 2 de Poesia digital: teoria, história, antologias. 
o uso tipográfico à maneira de poesia; "Estética e eletricidade", de Tristão de Alencar Araripe Júnior, também parece ser uma das primeiras relações claras entre literatura e ciência: o autor se refere à mudança de representação anteriormente existente (zigue-zague), nas artes, a partir dos registros fotográficos do raio.

A primeira metade do século XX apresenta uma série de poemas tipográficos que exploram a espacialidade das palavras e tratam, temática e iconicamente, da tecno-arte-poesia. O poema "Amar", de Oswald de Andrade e Ignacio da Costa Ferreira (Ferrignac ou Ventania), datado de 27 de julho de 1918, mostra uma intervenção criativa no carimbo; na verdade, toda a obra, que é um caderno, com duzentas páginas, é uma criação coletiva e colaborativa de Oswald de Andrade e seus amigos. Dentre vários poemas tipográficos de Mendes Fradique (pseudônimo de José Madeira de Freitas) há: o poema com a letra x, que se parece com uma vinheta, em Grammatica portugueza pelo methodo confuzo (1928) - o que o autor explica, por meio do nonsense, que o "X é o coringa do alfabeto; póde substituir todas as lletras" -, estabelecendo uma comparação com o "x", a incógnita, das equações matemáticas; e "Tapete persa", de Feira livre... (Anthologia nacional pelo METHODO CONFUSO) (1923), que está entre os primeiros poemas visuais no Brasil e parodia avant la lettre a pintura "A traição das imagens - Isto não é um cachimbo", de René Magritte, de 1929. "Máquina-deescrever", de Mário de Andrade, em Losango cáqui (1926), explora as características facilitadoras da máquina de escrever para produzir um poema com bastante espacialidade. Também há a apropriação temática dos textos publicitários por Paulo Mendes de Almeida, em Cartazes (1928); e, com temática semelhante e também do mesmo ano, "Poema do arranha-céu", em Martim Cererê(1944), de Cassiano Ricardo. Dentre alguns artistas e poetas brasileiros que refletem traços dadaístas, como Oswald de Andrade e Flávio de Carvalho, temos as fotomontagens de Jorge de Lima, que apareceram no Jornal Fronteiras, de Recife, em 1938, com o nome de "composições fotográficas", e na Revista Renovação, também de Recife, em 1941, denominadas de "poesia foto-plástica". Um conjunto de quarenta

5. Na revista Novidades de 24 de setembro de 1889.

6. ANDRADE. O perfeito cozinheiro das almas deste mundo, p. 109.

7. jornal publica quatro fotomontagens.

8. A revista publica as mesmas quatro fotomontagens do Jornal Fronteiras, com poemas de Vicente do Rego Monteiro, Ledo Ivo, Cláudio Tuiuti Tavares,Willy Lewin, Aluízio Medeiros, Américo de Torres Bandeira e Haydn Goulart. 
e uma fotomontagens está em A pintura em pânico, publicado no Rio de Janeiro em 1943, com um texto de apresentação de Murilo Mendes.

Na segunda metade do século XX, a poesia assume a busca de uma poesia total e procura elementos artísticos, de design e tecnológicos para incorporar ao fazer poético; é o tempo da poesia experimental ou do experimentalismo poético. A ave, de 1956, ${ }^{10}$ de Wlademir Dias-Pino, é um livro que "recebeu um tratamento de máquina, com suas folhas soltas, perfuradas, cortadas, codificadas em séries, etc., quase ao ponto de ser computador de bolso". ${ }^{11}$ Sobre a construção do livro, o próprio autor afirma: "Então eu percebi mais tarde que é o mesmo processo do computador, que você tem uma memória e que ela vai fornecendo." ${ }^{12}$ Sá afirma: "Poemas, à espera de máquinas que os possam ler, como "A Ave", já previam, em 1956, os trilhos magnéticos do computador." Também Solida (1956/ 1962) é considerado um "poema cibernético, movimento de uma função que se aprende $\mathrm{e}^{14} \mathrm{e}$ "precursor, o conjunto de textos". ${ }^{15}$ O plano-piloto para poesia concreta, de 1958, contém propostas que tratam de uma poesia em suas relações com as artes, design e tecnologias: "poesia concreta: produto de uma evolução crítica de formas, / dando por encerrado o ciclo histórico do verso (unidade / ritmico-formal), a poesia concreta começa por tomar / conhecimento do espaço gráfico como agente estrutural. espaço / qualificado: estrutura espácio-temporal, em vez de / desenvolvimento meramente temporístico-linear. daí a / importância da idéia de ideograma, desde o seu sentido geral / de sintaxe espacial ou visual, até o seu sentido específico". ${ }^{16}$ Fenômeno das décadas de 1960 e 1970, as fronteiras entre

9. Sob a curadoria de Simone Rodrigues, todo esse material foi reunido numa exposição na Caixa Cultural Rio de Janeiro - Galeria 1, da Caixa Econômica Federal, no Rio de Janeiro, no período de 15 de março a 02 de maio de 2010. Também foi publicado um catálogo bilíngue (português/inglês).

10. Idealizada em 1948, executada a partir de 1954, impressa em fins de 1955 e lançada em abril de 1956.

11. SÁ. Vanguarda: produto de comunicação, p. 104.

12. DIAS-PINO. Entrevista, p. 270.

13. SÁ. Vanguarda: produto de comunicação, p. 106.

14. SÁ. Vanguarda: produto de comunicação, p. 105.

15. PIGNATARI; PINTO. Nova linguagem, nova poesia, p. 161.

16. CAMPOS, A.; PIGNATARI; CAMPOS, H. Teoria da poesia concreta: textos críticos e manifestos: 1950-1960, p. 156. 
poesia e arte deixam de ser rígidas e isso motiva experimentações poético-artísticas, como por exemplo, "Lembra", de Ferreira Gullar, de 1959, que é um da série de poemas neoconcretos, que eram objetos tridimensionais, e requeriam a participação ativa do leitor, aos quais chamou de "não-objetos". Organismo (1960), de Décio Pignatari, é um flip book é um poema-objeto animado que cria um organismo à medida que o leitor folheia o poema-livro.

Há uma espacialidade que passa a ser incorporada ao fazer poético, influenciada pelas tecnologias de comunicação de massa, que vai desencadear uma visualidade, não apenas por meio da distribuição gráfico-espacial da letra e da palavra na página impressa (isso existe desde o final do século XIX), mas também pela inclusão da imagem à palavra, a poesia visual, a partir da década de 1970 . O leitor, que precisa realizar uma ação para que a obra produza mais significado, se torna um leitor-operador, de forma mais ativa do que aquele que, lendo um livro, ou ouvindo uma apresentação oral de poesia, interage com a obra por meio de sua mente e com o auxílio da imagem e das palavras que o livro lhe oferece. Neste caso, ocorre o uso da imaginação com a ação, enquanto que a poesia se torna um objeto de arte.

Joaquim Cardozo, poeta e engenheiro, apresenta, em boa parte dos seus poemas e obras, a assimilação da linguagem matemática e de conceitos científicos desde 1960, com Signo estrelado; "Visão do último trem subindo ao céu”, de 1970, uma aplicação poética da Teoria da Relatividade ao trem como meio de transporte no espaço e no tempo; uma interessantíssima partitura para o poema sonoro "Poema para uma voz e quatro microfones", de 1970; "Poemas sistema", "Poesia dos processos estocásticos (aleatórios)", ambos de 1976; e diversas poesias caligráficas e poesias visuais. Jeremias sem-chorar (1964), de Cassiano Ricardo, é um livro de poemas dedicados à ciência e à tecnologia, com as preocupações características da década de 1960: a desumanização produzida pela automação na sociedade urbana, o que representa uma nostalgia de um tempo anterior, especialmente quando afirma "Ó máquina, orai por nós" em "Ladainha", um poema irônico sobre a importância do cérebro eletrônico.

17. Flip book - Flick book (inglês britânico) ou folioscopio (espanhol). É um livro que contém uma série de textos ou imagens que variam gradualmente de uma página para a seguinte, para que, quando as páginas passam rapidamente, as imagens pareçam animar-se, simulando um movimento ou outra mudança. O primeiro flip book apareceu em setembro de 1868, quando foi patenteado por John Barnes Linnet. 
As tecnologias, especialmente as computacionais, mesmo em seus primórdios, passam a ser a temática de muitos poemas. "O computador", de Eno Theodoro Wanke, de 1968, se torna um registro interessante e especial: o poeta explica o que é um computador da sua época e o apresenta em forma de verso rimado e metrificado. Usar o soneto para falar da "mais humana máquina inventada" faz lembrar a programação a que o soneto está submetido: número de estrofes e de sílabas métricas, tipos de rimas, etc. E curiosamente o soneto faz parte de $O$ acendedor de sonetos, que, de certa forma, é uma referência a uma outra questão da tecnologia, a exemplo do soneto "O acendedor de lampiões", de Jorge de Lima, publicado em XIV Alexandrinos (1914), uma referência ao lampião de gás, anterior à luz elétrica, que modificou a paisagem noturna das cidades no final do século XIX. A ideia de uma máquina que parece pensar como o ser humano, ainda uma ficção, parece tomar conta da mentalidade da segunda metade do século XX. De 1969, temos a letra da canção "Cérebro eletrônico", de Gilberto Gil. "O novo homem", de Carlos Drummond de Andrade, de Os caminhos de João Brandão (1970), trata a chegada do robô de maneira apocalíptica: "o homem será feito / em laboratório. / Será tão perfeito / como no antigório." "Miséria e maravilha", em Os sobreviventes (1971), de Cassiano Ricardo, critica a existência do robô poeta, tradutor e pintor. "Metassoneto ou o computador irritado", de José Paulo Paes, de Meia página (1973), é um jogo cômico e criativo entre as rimas e as permutações realizadas em programas de computação. Merecem referência os vários números da Artéria, revista de poesia visual fundada em 1975, editada por Omar Khouri e Paulo Miranda, ${ }^{18}$ publicada em diferentes meios e suportes, dentre os quais o digital (volume 8, em 2003). Augusto de Campos e Julio Plaza, em Caixa preta (1975), criam figuras-poemas que oferecem a possibilidade de leituras não lineares, com amplas possibilidades interativas dos leitores. Dentre a produção vasta de Glauco Mattoso (pseudônimo de Pedro José Ferreira da Silva) em Jornal Dobrabil, de 1977 a 1981, e Revista Dedo Mingo (1982), os poemas visuais datilográficos ou datilograffiti ${ }^{19}$ "Poema concreto ou Computer-Art" e "Dream", ambos de 1982, são exemplos significativos do uso criativo da máquina de escrever, que certamente poderiam ser incluídos na antologia Typewriter Art (1975), editada por Alan Riddell. Paulo Leminski, com "Poesia", na revista Código (1978, nº 3), reúne conceitos de

18. Houve vários editores convidados para cada número da revista.

19. Denominação do poeta à sua fase visual: <http://glaucomattoso.sites.uol. com.br/fasevisual.htm>. 
poesia feitos por poetas e teóricos, dentre os quais vale destacar: "Uma das artes plásticas" (Mário Quintana), "Words Set to Music" (Dante/Pound), "Não é literatura" (Ezra Pound), "Design de linguagem" (Décio Pignatari), "Texto sem job e sem cliente" (um publicitário), e "01010110010111110" (Erthos Albino de Souza). Ele apresenta os conceitos contemporâneos de poesia e já coloca Erthos Albino de Souza como o poeta digital brasileiro, mostrando que já admite a existência da poesia digital.

As relações entre as artes, o jogo e os elementos combinatórios fascinam muitos poetas e os motivam a produzir poemas-objetos e poesias permutacionais. É o caso de QuebraPoema (1984), de Roberto C. Magalhães: dentro de uma caixa de papelão, há: três papéis, contendo uma introdução do autor, datada de 1984, dois poemas em folhas soltas e dois saquinhos de pano contendo pedaços de madeira com palavras. São dois poemas-geradores interativos: o leitor-operador escolhe um dos saquinhos e organiza os pedaços de madeira para a produção de um poema, como se montasse um quebra-cabeça, à semelhança de um poema digital interativo. Márcio Almeida, em "DIDeyeTICA: uma pós-leitura da Poesia Visual" (1985), apresenta um texto que é teórico, manifesto e proposta criativa, para uma nova leitura da poesia visual. Ślvio Roberto de Oliveira, em Terrabalada (1987), dedica dois interessantes poemas à tecnologia, fundindo um trabalho criativo com a palavra poética e com o vocabulário das novas tecnologias. Philadelpho Menezes, no canto inferior direito das páginas do catálogo da I Mostra Internacional de Poesia Visual de São Paulo (1988), apresenta o poema flip book "O inserto". José Santos, no número 18/19 de Dimensão: Revista Internacional de Poesia, publica "a viDa, quem ddiria / imita a minha / datilografia", de 1988, mostrando claramente a influência da tecnologia da escrita na produção de novos textos. O uso da máquina de escrever mostra a subjetividade de quem a usa. De maneira semelhante, a tecnologia computacional também deixa a sua marca no fazer poético. Sérgio Capparelli, em 33 ciberpoemas e uma fábula virtual (1996), livro infantojuvenil com ilustrações de Marilda Castanha, trata metaforicamente de um mergulho na cibercultura. Sangue cenográfico, de Leila Miccolis, reúne seus poemas de 1965 a março de 1997, dentre os quais a "Fase míc(r)olis ou micreira - série internet ${ }^{20}$ e o "Ciclo internet". ${ }^{21}$ Cadê? (1998), de Luís Turiba, reúne poesia visual, poesia digital, poesia musicada, entrevistas, depoimentos, arte visual e poesia

20. MiCCOLIS. Sangue cenográfico, p. 180-184.

21. MICCOLIS. Ciclo internet. 
visual digital. O poema visual "Caramuru??", de 1999, de Avelino de Araújo, de Abrapalavra, a partir de uma impressão gestáltica, é um exemplo da contaminação temática e da inclusão do computador em nossa vida.

Exemplos, como os comentados nos parágrafos anteriores, continuam a aparecer nas mais diferentes publicações e adentram o século XXI: Burrocracia (2003), de Franklin Valverde, um livro de poemas feito com carimbos; Música (2005), de Celso Borges, adota o formato circular do disco para uma poesia visual e sonora; Cafunés em potencial: romance digital (2008), de Daniel Santiago, é uma obra de 252 páginas compostas de zeros e, apesar do subtítulo, é um poema-cafuné à mãe do poeta; Vera Casa Nova, na Antologia dez faces, apresenta "à moda de manifesto: as poéticas experimentais e outros que tais", seguido dos poemas visuais de Marcelo Kraiser; As façanhas de um jovem Don Juan (2009), de Amir Brito Cadôr, é um flip bookem que as variações de duas letras produzem uma variedade de pares de seios femininos; Manual de acrobacias n. 1 (2010), de Carlos Augusto Lima, com setenta e dois poemas dedicados a todos os seus amigos (na verdade, é um único poema que pode ser lido de forma diferente por quem o escolher); Tecnopoética (2010), de Alexandre Dacosta, que faz poemas a partir de fotos de objetos industriais, material de uso diário, retomando o conceito duchampiano de ready made.

\section{Historia 2: a partir do computador até os dias atuais}

Podemos estabelecer o início da poesia digital no Brasil a partir de três momentos precursores: o "Poema elétrico" de Albertus Marques em novembro de 1960; a publicação colaborativa Vogaláxia, de Pedro Xisto, Erthos Albino de Souza e Kamergorodski (1966); a publicação colaborativa entre Pedro Xisto e Leslie Gabriel Mezei para as variações feitas em computador a partir do poema "(B)ABEL", no Festival de Inverno em Toronto, Canadá, em 1968; a primeira experiência artística com computador, "Abecê", de 1968, idealizado por Waldemar Cordeiro, com a colaboração de Giorgio Muscati, físico da Universidade de São Paulo. Todos esses poemas precursores parecem anunciar a série de poemas

\footnotetext{
22. A antologia tem prefácio de Rogério Barbosa da Silva e contém obras de Adriana Versiani, Álvaro Andrade Garcia, Ana Caetano, Camilo Lara, Carlos Augusto Novais, Luciana Tonelli, Marcelo Dolabela, Vera Casa Nova e Marcelo Kraiser.
} 
concretos feitos em computador por Erthos Albino de Souza em 1972, intituladas Le tombeau de Mallarmé, distribuída individualmente pelo poeta aos seus amigos e publicada no livro Mallarmé(1974), na tradução de Augusto e Haroldo de Campos e Décio Pignatari.

Podemos estabelecer como marco precursor o "Poema elétrico", de Albertus Marques, como um dos desdobramentos interessantes dessa poesia-objeto interativa e também filiado à poesia neoconcreta, que pode ser considerado como o tempo pioneiro de uma experiência poética com os meios eletrônicos. ${ }^{23}$ O poeta afirma que a "palavra, impressa, não me poderia servir. Só a luz poderia provocar o fenômeno e a carga requerida. Só a luz poderia fazer aparecer e desaparecer, e, portanto, transmitir, a idéia real e a carga poética desejada”. ${ }^{24}$ Foi, então, criado um poema elétrico, cuja energia foi fornecida por meio de pilhas. À semelhança das futuras poesias eletrônicas, e lembrando o 0 (zero) e 1 (um) do sistema binário, o poema exige a interação do leitor que vai produzir significados a partir do campo branco, do botão e de sua iniciativa de apertá-lo. Em seguida, vem "Álea I variações semânticas", de Haroldo de Campos, de 1963, um poema que usa o conceito matemático de permutação para realizar um programa para uma leitura de múltiplas possibilidades. O manifesto "Nova linguagem, nova poesia", de Luiz Angelo Pinto e Décio Pignatari, de 1964, aponta a linguagem do computador eletrônico, dentre outras linguagens, como adequada para a poesia semiótica, que propõe a criação de novos signos e novos significados.

O desenvolvimento da tecnologia e das máquinas e o aparecimento do computador passam a fazer parte das reflexões dos poetas: as relações entre poesia, arte, ciência e tecnologia computacional passam a ser temas de muitas poesias. Mapear algumas delas nas décadas de 1960 a 1980 pode auxiliar o entendimento da assimilação da tecnologia como tema e ajuda a compreender o percurso da poesia verbal impressa para a poesia visual, para a poesia tridimensional ou poesia-objeto e para a poesia eletrônica. Erthos Albino de Souza ${ }^{25}$ afirma que a

23. Nos anos de 1980, o poeta fez uma série de poesias digitais utilizando linguagem Basic de programação.

24. MARQUES. Poesia neoconcreta não objeto: poema elétrico, p. 156.

25. Essa entrevista, concedida a Carlos Ávila, foi publicada pela primeira vez no jornal Estado de Minas, Belo Horizonte, em 12 jan. 1983, sob o título de "Com a palavra, Erthos: os novos códigos e a poesia", e foi republicada parcialmente, com o título de "O engenheiro da poesia", na revista Bric-a-Brac, Brasília, 1989. ÁVILA. Poesia pensada, p. 99. 
sua primeira experiência em poesia de computador, na realidade, não foi com computador. Foi uma releitura do poema "Vogaláxia", do Pedro Xisto.

O Xisto fez um projeto de poema, com permutação das vogais e repetição. E ele me pediu para executar, porque eu era engenheiro e entendia disso. Então eu fui fazer e fiz aquilo na mão, na mão mesmo. É uma trabalheira, você tem que ter um cuidado tremendo. Na época eu não tinha condição de fazer no computador. Fiz assim mesmo e editei na Bahia, em $66^{26}$

O uso de procedimentos matemáticos na poesia, especialmente aqueles usados na linguagem de programação de computador, tem sido o grande motivador da produção da poesia eletrônica. As poesias digitais podem ser agrupadas com base nos estágios das tecnologias computacionais, ou seja, até 1995 (uso artístico e poético das redes digitais) e depois de 1995 até os dias atuais.

Da poesia digital antes da rede, vale citar os seguintes poemas: "Soneto só pra vê", de Daniel Lima Santiago, de 1982; "Rejoyce”, de João Coelho, de 1985; "A onda", de Roberto Keppler; "Chuva", de Albertus Marques, de 1987; "Retrato em preto e branco", de Luís Dohlnikoff, de 1987; em março de 1987, a criação da Oficina Literária Informatizada (OLI) em Belo Horizonte, composta por Álvaro Andrade Garcia, Roberto Barros de Carvalho, Delfim Afonso Jr. e Mário Flexa, com o objetivo de "abrir espaço para a veiculação de seus trabalhos através da acoplagem do computador ao telão do vídeo"; ${ }^{27}$ Tudos, livro de poesia visual digital de Arnaldo Antunes; as poesias visuais digitais de Arnaldo Antunes e Augusto de Campos em Rimbaud livre, de 1993; Nome, livro, brochura e DVD de videopoesia; "Poemas em pps", de Lucio Agra, em 1994/1995; Mais fractais, de Goulart Gomes, de 1996; Algorritmos, infopoesias de E. M. de Melo e Castro, ${ }^{28}$ dentre outras. ${ }^{29}$

A partir de 1995, o número de poetas digitais cresceu bastante, desde os pioneiros "Poemas em computador" (Gilbertto Prado e Alckmar Luiz dos Santos)

26. SOUZA. Entrevista cedida a ÁVILA. Poesia pensada, p. 64.

27. ALMEIDA. Poesia visual na década de 80: Oficina literária informatizada, p. 10.

28. Melo e Castro, que atualmente reside em São Paulo, é um dos poucos poetas portugueses contemporâneos cuja obra atual, a partir das suas infopoesias de 1996, faz parte da poesia digital no Brasil. Ele sempre brinca que é $15 \%$ brasileiro.

29. Não foi possível incluir outras obras do mesmo feitio que surgiram a partir de 1995 até os dias atuais, pois estaria fora dos limites de um artigo. 
e "Verso universal" (coordenação de Philadelpho Menezes), ambos de 1995. Com os recursos de comunicação quase instantânea, inicialmente dos e-mails e dos grupos eletrônicos de discussão, e, agora, das redes sociais e das tecnologias móveis, o intercâmbio com poetas digitais de outros países aumentou, a participação de brasileiros em eventos internacionais ensejou criações individuais e colaborativas, que cresceram sensivelmente com o surgimento do YouTube, em 2005, capaz de resgatar as videopoesias dos anos de 1970 a 1990. Esse volume de poesias digitais em rede motivou a criação de antologias nacionais e internacionais, que representam mapeamentos muito importantes para a compreensão do movimento internacional, descentralizado e sem manifestos que é a tecno-arte-poesia.

O sítio Arte visual, depois Poema visual, organizado por Hugo Pontes e Vitor Hugo Manata Pontes a partir de 1996, ${ }^{30}$ em Poços de Caldas, MG, é uma iniciativa pioneira no Brasil na divulgação de diferentes tipos de poesia. É a primeira antologia da poesia visual na rede eletrônica e, com o passar do tempo, inclui arte postal e poesia digital. Também pioneiro na divulgação da poesia experimental no Brasil, reunindo exemplos de vários países, o sítio EPE - Estudo de poesia experimental, ${ }^{31}$ sob a coordenação de Philadelpho Menezes (1950-2000), iniciado em outubro de 1996, apresenta poesia visual, sonora e digital. ${ }^{32}$

Ao invés de apresentar uma longa lista de poetas e poemas digitais a partir de 1995, optou-se por mapear as antologias mais representativas feitas no Brasil e as existentes no exterior, mas que necessariamente contêm autores brasileiros. Foram incluídas as antologias de videopoesias e poesias sonoras, porque elas são consideradas, de uma forma geral, por muitos estudiosos, como poesias eletrônica: 1985-2002 - Perhappiness - Concurso Nacional de Clipoemas - Fundação Cultural de Curitiba - concursos de videopoesias em homenagem a Paulo Leminski - trata-se de um acervo significativo para a compreensão da videopoesia brasileira.

1992 - Poesia sonora: poéticas experimentais da voz no século XX Philadelpho Menezes (1960-2000) (Ed.) - antologia de textos teóricos sobre poesia fonética e poesia sonora.

30. www.poemavisual.com.br.

31. É também um acervo de poesia experimental, que se encontra na Biblioteca Central da PUC-SP.

32. <http://www.pucsp.br/pos/cos/epe/ape/index.html s. 
1995 - Poetry - New Media - Links of Imagination - Jim Andrews (Org.) (Canadá) - é um dos mais amplos mapeamentos feitos por uma única pessoa: <http://vispo.com/misc/links.htm>; Vórtice Argentina-contém arte postal, poesia visual, poesia experimental e poesia digital: <http:// www.vorticeargentina.com.ar/>; New Media Poetry: Poetic Innovation and New Technologies - Visible Language (EUA) v. 30.2 - Eduardo Kac - revista impressa com textos teóricos e algumas poesias visuais digitais.

1996 - Poesia sonora: do fonetismo às poéticas contemporâneas da voz Philadelpho Menezes (Coord.) - CD.

1998 - PopBox - Elson Fróes (Org.) - poesia verbal, poesia visual, poesia sonora, poesia digital, ensaios e pesquisas: <http://www.elsonfroes.com.br/>; Antonio Risério - Ensaio sobre o texto poético em contexto digital livro; Karenina.it Experimental poesia in funzione fática - Caterina Davinio (Org.) (Itália) - Projeto de comunicação on linee em rede, com base na teoria da função fática da linguagem, de Roman Jakobson, que trata do uso da linguagem com o objetivo de manter aberto e operativo o canal de comunicação entre os interlocutores: <http://www.geocities. com/Paris/Lights/7323/kareninarivista.html>; Poesia sonora: do fonetismo às poéticas contemporâneas da voz-Philadelpho Menezes (Org.) - antologia brasileira - CD.

2000 - Poesia visual, hipertexto e ciberpoesia - <http://revistaseletronicas. pucrs.br/ojs/index.php/revistafamecos/article/viewFile/3082/2358> Sérgio Capparelli, Ana Cláudia Gruszynski e Gilberto Kmohan (Org.); Brazilian Digital Art and Poetry on the Web-Jorge Luiz Antonio (Org.) - panorama da arte e da poesia digital no Brasil: <http://www.vispo.com/ misc/BrazilianDigitalPoetry.htm>.

2001 - Voicimage - Visible Language 35.1 - Enzo Minarelli - revista impressa - Antologia com dez estudos sobre poesia sonora, dentre os quais o Manifesto da Polipoesia. Ladrão de fogo, brochura e CD; Ricardo Corona, poesia visual e poesia sonora em diálogo com os seus poetas preferidos; Cacograma, brochura e CD, poesia visual e poesia sonora de Ana Caetano, Carlos Augusto Novais, Emilia Mendes, Jair Tadeu, Juca, Levi Carneiro, Luciano Cortez, Marcelo Dolabela. 
2002 - Tecno-Poesia e realtà virtuali - Caterina Davinio (Ed.) - livro que estabelece tipologias e cataloga cento e trinta autores de vários países; Museu do essencial e do além disso - Regina Célia Pinto (Ed.) - mapeamento de arte e poesia digitais, muitos projetos e uma Seção de Poesia Digital: $<$ http://www.arteonline.arq.br/museu/poesiadig.htm>; Poesia e tecnologia, capítulo de Panorama de arte e tecnologia no Brasil - Instituto Itaú Cultural - Arlindo Machado, Silvia Laurentiz e Fernando Iazzetta (Org.) estudo teórico e antológico: <http://www.cibercultura.org.br/tikiwiki/tikiindex.php?page=poesia+e+novas+tecnologias $>$; seção de Criação on line da Biblioteca Virtual de Literatura - <http://www.bibvirtuais.ufrj.br/ literatura/asp/SaidaCat.asp?cod=71\&id=port $>-$, organizado pela PACC/ UFRJ (Programa Avançado de Cultura Contemporânea da Universidade Federal do Rio de Janeiro (Brasil), panorama da poesia e literatura digitais.

2003 - Cortex Revista de Poesia Digital - Lucio Agra, Thiago Rodrigues e Guilherme Ranoya (Ed.) - CD-ROM; Alckmar Luiz dos Santos - Leituras de nós: ciberespaço e literatura - livro e CD-ROM; Arteria 8 - Omar Khouri e Fábio Oliveira Nunes (Ed.) - CD-ROM e sítio: <http://www. arteria8.net> - Artéria é uma revista de poesia visual fundada em 1975 por Omar Khouri e Paulo Miranda e vem sendo editada nos mais diferentes suportes.

2004 - Atualidade - Errática - André Vallias e Eucanaã Ferraz (Ed.): <http:// www.erratica. com.br>.

2005 - Mostra Internacional de Poesia Visual - Amir Brito Cadôr (Cur.) $<$ http://www.iar.unicamp.br/alunos/poesiavisual/inicial.htm>-; Mostra Internacional de Poesia Visual e Eletrônica - Jorge Luiz Antonio, Hugo Pontes, Roberto Keppler (Cur.) - catálogo da exposição: <http:// arteonline.arq.br/museu/library_pdf/interface.html>; Literatura $\varepsilon$ informática - José Luís Jobim (Org.) - livro; Memória, literatura e tecnologia - Benedito Antunes (Org.) - livro; Caminhos cruzados: literatura e informática-Adair de Aguiar Neitzel e Alckmar Luiz dos Santos (Org.) - livro; Portal Cronópios - <http://www.cronopios.com.br $>-$ Pipol (José Waldery Mangieri Pires) (Ed.) - textos criativos e teóricos da literatura contemporânea. 
2005-2006 - Portal de Ciberliteratura - Rui Torres (Ed.) - Estudo teórico e criativo (releituras digitais da Poesia Experimental Portuguesa): <http://www.poex.net/ciberliteratura/>.

2006 - E-Poemas inéditos - Folha On Line - Antologia com muita representatividade: <http://www1.folha.uol.com.br/folha/treinamento/ novoemfolha41/te21062006033.shtml>; 2006 - atualidade Cibertextualidades - Universidade Fernando Pessoa, Portugal - revista impressa e digital.

2006-2007 - 6X - Juliana Teodoro e aLe (Ed.) (Brasil) - CD-ROM e sítio: <http:// www.youtube.com/opioptico\#p/c/20A03EA3F4190950>.

2007 - Denise Azevedo Duarte Guimarães (Brasil) - Comunicação tecnoestética nas mídias audiovisuais - livro; Media Poetry: An International Anthology-Eduardo Kac (Brasil/EUA) (Ed.) - antologia; Sonorizador, Ricardo Corona, brochura e CD, reúne poetas e artistas em poesias verbais, visuais e sonoras.

2008 - Ciberespaço: mistificação e paranóia - Alamar Aquino Corrêa (Org.) livro; N. Katherine Hayles (EUA) - Electronic Literature: New Horizons for the Literary - livro e CD-ROM - traduzido para o português somente livro impresso, Literatura eletrônica: novos horizontes para o literário em 2009 pela Editora Universidade Passo Fundo.

2009 - Enter antologia digital - Heloísa Buarque de Hollanda (Ed.) - Antologia e estudo teórico a respeito da literatura na rede: $<$ http://www.oinstituto. org.br/enter>; 1ํㅗimpósio Virtual de Poesia: diálogo sobre a arte de Dante na pós-modernidade - Márcio Almeida (Coord.): <http://www. germinaliteratura. com.br/2009/literatura_out2009_marcioalmeida_ 1.htm>; Poesia sonora: história e desdobramentos de uma vanguarda poética-Brenda Marques Pena - livro.

2010 - Jorge Luiz Antonio - Poesia digital: teoria, história, antologias, livro e DVD; Literatura latinoamericana, española, portuguesa en la era digital (nuevas tecnologías y lo literario) - Arizona Journal of Hispanic Cultural Studies (EUA) - revista impressa; Questões de literatura na tela - Miguel Rettenmeier e Tania Rösing (Org.) - livro impresso. 
As antologias impressas e digitais acima listadas oferecem um panorama significativo da poesia digital no Brasil, em sua grande maioria, e oferecem subsídios importantes aos interessados em estudar esse tema tão contemporâneo, pois os mapeamentos que elas abrangem são considerados como um conjunto de acervos de um movimento poético internacional, do qual o Brasil faz parte integrante, e ensejam estudos teóricos sob os mais diferentes pontos de vista.

\section{Agradecimentos}

A pesquisa por mim realizada não seria possível se eu não tivesse o apoio de todos os poetas e artistas citados neste artigo, bem como de seus herdeiros e representantes legais, a quem agradeço a possibilidade de registrar tudo o que foi possível nos limites deste artigo.

Reservo um agradecimento especial à FAPESP (Fundação de Amparo à Pesquisa do Estado de São Paulo), que me concedeu uma bolsa de pós-doutorado para pesquisas no Instituto de Estudos da Linguagem na Universidade Estadual de Campinas, sob a supervisão do Prof. Dr. Paulo Franchetti.

Uma das formas de agradecimento ao supervisor, à FAPESP e ao IEL-UNICAMP, que me pareceu válida, foi a criação do Arquivo de Tecno-Arte-Poesia, com o auxílio da reserva técnica da bolsa e as generosas doações de pessoas e instituições, ${ }^{33}$ contendo livros e periódicos impressos e digitais, disponível na biblioteca do IEL-UNICAMP para a continuação das pesquisas.

\section{Techno-Art-Poetry in Brazil}

Abstract: Can we geographically delimitate digital poetry and name it as Brazilian, North-American, German, French, and so on? From this question on, the article presents a panorama view of techno-art-poetry in Brazil before and after the coming of individual and collective computers.

Keywords: contemporary Brazilian poetry, poetry and new technologies, techno-art-poetry.

33. Até o mês de julho/2011, há 129 títulos adquiridos (livros e periódicos) e 60 doados por 29 pessoas e/ou instituições. 


$$
\text { Referências }
$$

ALMEIDA, Márcio. DidEYEtica: uma pós-leitura da Poesia Visual. Minas Gerais, 17 jun. 1989. Caderno Suplemento Literário, p. 6-7. Também disponível em: <http:// www.letras.ufmg.br/websuplit/exbGer/exbSup.asp?Cod=22112406198902>. Acesso em: 20 jan. 2010.

ALMEIDA, Márcio. Poesia visual na década de 80: Oficina literária informatizada. Minas Gerais, 17 jun. 1989. Caderno Suplemento Literário, p. 10-11. Disponível em: <http://www.letras.ufmg.br/websuplit/exbGer/exbSup.asp?Cod=2211240619891022112406198911>. Acesso em: 26 jan. 2010.

ANDRADE, Oswald de. O perfeito cozinheiro das almas deste mundo. São Paulo: Globo, 1992.

ANTONIO, Jorge Luiz. Poesia digital: teoria, história, antologias. São Paulo: FAPESP; Navegar; Itu: Autor; Columbus, Ohio, EUA: Luna Bisontes Prods, 2010. Acompanha DVD.

ANTONIO, Jorge Luiz. Poesia hipermídia: estado de arte. In: RETTENMAIER, Guilherme; RÖSING, Tânia (Org.). Questões de literatura na tela. Passo Fundo: UPF, 2011. p. 123-149.

Ávila, Carlos. Poesia pensada. Rio de Janeiro: 7Letras, 2004.

CAMPOS, Haroldo de. Álea 1: variações semânticas (uma epicomédia de bolso). In: SIMON, Iumna Maria; DANTAS, Vinicius de Avila (Org.). Poesia concreta. São Paulo: Abril Educação, 1982.

CASTro, E. M. de Melo e. Algorritmos: infopoemas. São Paulo: Musa, 1998.

CASTRO, E. M. de Melo e. Infopoesia: produções brasileiras (1996-99). Disponível em: <http://www.ociocriativo.com.br/meloecastro>. Acesso em: 20 maio 2001

CASTRO, E. M. de Melo e. Livro de releituras e poiética contemporânea. Belo Horizonte: Veredas \& Cenários, 2008. Acompanha DVD.

CASTRO, E. M. de Melo e. Máquinas de trovar: poética e tecnologia. Évora: Intensidez, $2008 \mathrm{a}$.

CASTRO, E. M. de Melo e. O paganismo em Fernando Pessoa e sua projeção no mundo contemporâneo: ensaio bibliográfico e hermenêutico. São Paulo: Annablume, 2011.

CORRÊA, Alamir Aquino (Org.). Ciberespaço: mistificação e paranóia. Londrina: UEL, 2008.

COZER, Raquel. Diálogo poético entre o clássico e o moderno na web. O Estado de S. Paulo, caderno Sabático, 23 out. 2010, p. S4-S5. Disponível em: <http:// www.bv.fapesp.br/namidia/noticia/40461/dialogo-poetico-classico-p-moderno/>. Acesso em: 27 out. 2010.

DIAS-PINO, Wlademir. Processo: linguagem e comunicação. Petrópolis: Vozes, 1971.

DIAS-PINO, Wlademir. Entrevista. In: SILVEIRA, Paulo. A página violada: da ternura à injúria na construção do livro de artista. Porto Alegre: UFRGS, 2001. p. 268-275. Entrevista concedida a Paulo Silveira no Rio de Janeiro, em 17 mar. 1999.

FRANCHETTI, Paulo. Alguns aspectos da teoria da poesia concreta. 3. ed. Campinas: Unicamp, 1993.

FRANCHETTI, Paulo. Estudos de literatura brasileira e portuguesa. Cotia: Ateliê, 2007. 
FRANCHETTI, Paulo. Poesia e técnica: poesia concreta. Sibila: poesia e cultura. São Paulo, [2009]. Disponível em: <http://www.sibila.com.br/index.php/critica/765-poesiae-tecnicapoesia-concreta>. Acesso em: 23 jan. 2010.

FRANCHETTI, Paulo. Poesia digital. Cronópios, São Paulo, 24 fev. 2010a. Disponível em: <http://www.cronopios.com.br/site/internet. asp?id=4426>. Acesso em: 25 fev. 2010 .

FREITAS, Mirian de. A literatura da Era Digital. Literatura Conhecimento Prático, São Paulo, n. 28, p. 24-29, 2010

GUIMARÃES, Denise Azevedo Duarte. Comunicação tecnoestética nas mídias audiovisuais. Porto Alegre: Sulina, 2007.

HOLlanda, Heloísa Buarque de (Org.). Enter antologia digital. Rio de Janeiro: O Instituto (Instituto Contemporâneo de Projetos e Pesquisa), ago. 2009. Disponível em: <http://www.oinstituto.org.br/enter>. Acesso em: 23 out. 2010.

JOBIM, José Luís (Org.). Literatura \& informática. Rio de Janeiro: FAPERJ; Eduerj, 2005.

KAC, Eduardo. Luz e letra: ensaios de arte, literatura e comunicação. Rio de Janeiro: Contracapa, 2004.

LARA, Camilo; NOVAIS, Carlos Augusto; DOLABELA, Marcelo (Org.). Antologia dez faces. Belo Horizonte: O Lutador, 2008.

MARQUES, Albertus. Poesia neoconcreta não objeto: poema elétrico. In: AMARAL, Aracy A. (Coord.). Projeto construtivo brasileiro na arte: 1950-1962. Rio de Janeiro: Museu de Arte Moderna; São Paulo: Pinacoteca do Estado, 1977. p. 156.

MENDONÇA, Antônio Sérgio; SÁ, Alvaro. Poesia de vanguarda no Brasil: de Oswald de Andrade ao poema visual. Rio de Janeiro: Antares, 1983.

MENEZES, Philadelpho; AZEVEDO, Wilton. Interpoesia: poesia hipermídia interativa. São Paulo: Universidade Presbiteriana Mackenzie/Estúdio de Poesia Experimental da PUC-SP/FAPESP, 1997/1998. CD-ROM.

MICCOLIS, Leila. Sangue cenográfico. Rio de Janeiro: Blocos, 1997.

MICCOLIS, Leila. Ciclo internet. Rio de Janeiro: 1997a. Disponível em: <http:// www.blocosonline.com.br/sites_pessoais/sites/lm/leila/leilacnt.htm>. Acesso em: 23 jul. 2008.

MINARELli, Enzo. Polipoesia: entre as poéticas da voz no século XX. Tradução de Frederico Fernandes. Londrina: Eduel, 2010. Acompanha um CD

NEITZEL, Adair de Aguiar. O jogo das construções hipertextuais. Florianópolis: UFSC; Itajaí: UNIVALI, 2009.

NEITZEL, Adair de Aguiar; SANTOS, Alckmar Luiz dos (Org.). Caminhos cruzados: informática e literatura. Florianópolis: UFSC, 2005.

PADIN, Clemente. La poesía experimental latinoamericana: 1950-2000. Tradução de Yolanda Péres Herreras. Colmenar Viejo: Información y Producciones, S. L., 2000.

PENA, Brenda Marques. Poesia sonora: história e desdobramentos de uma vanguarda poética. Belo Horizonte: Tradição Planalto, 2009.

PIGNATARI, Decio; PINTO, Luiz Angelo. Nova linguagem, nova poesia. In: CAMPOS, Augusto de; PIGNATARI, Décio; CAMPOS, Haroldo de (Org.). Teoria da Poesia Concreta: textos críticos e manifestos: 1950-1960. 2. ed. São Paulo: Duas Cidades, 1975. p. 159-171. 
QUEIROZ, Sônia. Poesia em imagens, sons \& páginas virtuais. In: MARINHO, Marildes (Org.). Ler e navegar: espaços e percursos da leitura. Campinas: Mercado de Letras/ Associação de Leitura do Brasil - ALB, 2001. p. 161-190.

SÁ, Álvaro. Vanguarda: produto de comunicação. Petrópolis: Vozes, 1977.

SAMUEL, Rogel. Novo manual de teoria literária. 4. ed. Petrópolis: Vozes, 2007.

SANTOS, Alckmar Luiz dos. Leituras de nós: ciberespaço e literatura. São Paulo: Itaú Cultural, 2003. Acompanha CD-ROM.

SILVA, Rogério Barbosa da. Tecnopoéticas: poesia, hipertexto e tecnologias digitais. In: RIBEIRO, Ana Elisa; VILELA, Ana Maria Nápoles; COURA SOBRINHO, Jerônimo; SILVA, Rogério Barbosa da (Org.). Leitura e escrita em movimento. São Paulo: Peirópolis, 2010. p. 83-95.

SIMON, Iumna Maria; DANTAS, Vinicius de Avila (Org.). Poesia concreta. São Paulo: Abril Educação, 1982. (Literatura Comentada).

TELES, Gilberto Mendonça (Org.; Trad.). Vanguarda européia e modernismo brasileiro: apresentação e crítica dos principais manifestos, prefácios e conferências vanguardistas, de 1857 a 1972. 17. ed. Petrópolis: Vozes, 2002.

VICENTIN, Carolina. Letras digitais: o avanço da informática permite o surgimento de novos estilos literários. Correio Braziliense, Brasília, 12 jan. 2011. Caderno Eu, Estudante, p. 22

XISTO, Pedro; SOUZA, Erthos Albino de; KAMERGORODSKI, Bernardo C. Vogaláxia. São Paulo: Invenção; Salvador: Artes Gráficas, 1966. 